\title{
Translation and cultural adaptation of the Mother-Generated Index into Brazilian Portuguese: A postnatal quality of life study
} \author{
Ana Karina Bezerra Pinheiro, PhD (Professor) ${ }^{\mathrm{d}}$ \\ a Universidade Federal do Ceará. Fortaleza, CE, Brazil \\ ${ }^{\mathrm{b}}$ Mother and Infant Research Unit, University of Dundee, Dundee DD1 4HJ, Scotland UK \\ ${ }^{\mathrm{c}}$ Maternidade Escola Assis Chateubriand, Ceará, Brazil \\ d Department of Nursing, Universidade Federal do Ceará, Fortaleza, CE, Brazil \\ ${ }^{\text {e } U n i v e r s i d a d e ~ E s t a d u a l ~ d o ~ C e a r a ́, ~ F o r t a l e z a, ~ C E, ~ B r a z i l ~}$
}

Samila Gomes Ribeiro, MNHP (Doctoral student in Nursing Health Promotion)a Andrew Graham Symon, RM, PhD (Senior Lecturer) ${ }^{\mathrm{b}, *}$, Paula Renata Amorim Lessa, MNHP (Doctoral student in Nursing Health Promotion) ${ }^{a}$, Mirna Fontenele de Oliveira, PhD (Women's Health Nurse Practitioner) ${ }^{c}$, Priscila de Souza Aquino, PhD (Professor) ${ }^{\mathrm{d}}$, Paulo César de Almeida, PhD (Professor of the Practice of Statistics)

\section{A R T I C L E I N F O}

\section{Article history:}

Received 31 July 2014

Received in revised form

28 January 2015

Accepted 26 March 2015

\section{Keywords:}

Postnatal

Quality of life

Questionnaire

Translation

Cultural adaptation

Brazil

\begin{abstract}
A B S T R A C T
Objective: quality of life issues are central to maternal health and well-being. Within the context of a study examining postnatal quality of life, we set out to translate into Brazilian Portuguese the MotherGenerated Index and ensure its cross-cultural adaption for use in a Brazilian context.

Design: the Mother-Generated Index, a subjective quality of life tool, underwent a validated process of translation and cultural adaptation: synthesis of two independently translated versions, back-translation and review by an expert committee was followed by testing of the preliminary tool with 30 mothers. Settings: community-based study in city in north-eastern Brazil.

Participants: 30 postpartum mothers, interviewed approximately 30 days after birth.

Findings: while the mothers understood the concept of identifying and scoring quality of life aspects, many did not grasp the concept behind the use of 'spending points' to produce a relative ranking of these aspects. We resolved this by giving the mothers 'spending beans' instead; beans are a regional food staple. This use of a physical 'currency' solved the problem.

Discussion: this modified approach was ratified by the committee of experts and used with success on a further sample of 91 mothers. The whole process aimed to ensure semantic equivalence of the translated tool, and following this process we concluded that face validity of the Brazilian Portuguese MotherGenerated Index was good. While considerable resources are required to ensure a robust process of translation and adaptation, this is necessary if valid and reliable tools are to be produced. Implications. We conclude that the Mother-Generated Index is a valid tool to measure quality of life among Brazilian postpartum mothers, as it allows a simple and understandable way of assessing the various dimensions involved in their quality of life. Moreover, the Mother-Generated Index can provide healthcare professionals the opportunity to become aware of all significant aspects of a woman's life after childbirth. (c) 2015 Elsevier Ltd. All rights reserved.
\end{abstract}

\footnotetext{
* Corresponding author.

E-mail addresses: samilaribeiro@yahoo.com.br (S.G. Ribeiro) a.g.symon@dundee.ac.uk (A.G. Symon), paularenatal@yahoo.com.br (P.R.A. Lessa), mirnafontenele@yahoo.com.br (M.F. de Oliveira), priscilapetenf@gmail.com (P.d.S. Aquino), pc49almeida@gmail.com (P.C. de Almeida), anakarinaufc@hotmail.com (A.K.B. Pinheiro).
}

\section{Introduction}

The postnatal period is characterised by change: in addition to physiological adjustment, a complex interplay of emotional, social, psychological, sexual and spiritual adaptation renders this a unique and complex time. Kanotra et al. (2007) found that postnatal women cited needs relating to (among other things) social support, breast feeding, education about caring for their baby, and depression. All of these factors affect women's health 
and well-being, and healthcare practitioners need to acknowledge this multifaceted reality (Yelland, 2010). A range of satisfaction scales, Patient-Reported Outcome Measures (PROMs) and PatientReported Experience Measures (PREMs), has emerged in recent years as healthcare providers have sought to evaluate effectiveness and demonstrate their 'patient-centredness' (HSCIC 2014; Mapi Research Trust, 2014). Within maternity care standard postnatal assessments which assess physiological and psychological change have been augmented by other assessments of well-being and quality of life (Kyser et al., 2012; Mogos et al., 2013). Being a complex and all-embracing reality, quality of life may be affected by many factors, including physical, mental, emotional, social, sexual and spiritual well-being. Health and well-being are clearly important determinants of quality of life, which Calman (1984): 124 defines as the extent to which hopes and ambitions are matched by experience'. He goes on note that the aim of medical care is to 'narrow the gap between a patient's hopes and aspirations and what actually happens' (Calman, 1984: 124). In addition to generic quality of life tools such as WHO QoL there are instruments specifically designed for postnatal use (e.g. Symon et al., 2003b; Hill et al., 2006). However, there is a heavy bias towards instruments designed for use in English-speaking populations.

In Brazil the high level of obstetric intervention has received considerable attention over the years (Barros et al., 1991; Potter et al., 2001; Declercq, 2014; Leal et al., 2014), and the importance of postnatal morbidity has more recently been recognised (Souza et al., 2006; Mogos et al., 2013). However, there is a lack of evidence regarding postnatal well-being and quality of life in Brazil, and there are no validated quality of life tools specifically for the Brazilian context. A home visit within the first postnatal week by a member of the family's health team (usually the nurse; occasionally the doctor) is a requirement in Brazil (Ministry of Health, Brazil, 2012). However, there are concerns that contact with health professionals over the next month focusses exclusively on neonatal well-being (Ministry of Health, Brazil, 2005), with the result that maternal well-being is often overlooked (Pereira and Gradim, 2014). Similar concerns have also been raised in the UK (Yelland, 2010).

Postnatal women may experience many things in common but there is also something unique in each case. Assessments of quality of life have the potential to help improve maternal health, but philosophical objections have been raised about the use of instruments which purport to identify subjective experiences and yet which specify the domains to be examined. However rigorously developed, there is no guarantee that the tool will capture what is most important to that mother at that time. As our ultimate intention is to enable nurses and other healthcare professionals in Brazil to become aware of postnatal women's main concerns we selected the Mother-Generated Index (MGI) (Symon et al., 2003b). The MGI identifies subjective quality of life. Identifying what each woman considers to be important, from whatever domain in her life, is an important step in promoting woman-centred care, since it allows health professionals to target interventions. The MGI has already been validated in Scotland (Symon et al., 2003b), India (Nagpal et al., 2008) and Iran (Khabiri et al., 2013). It has also been used in Poland (Nowakowska-Głab et al., 2010), Portugal and China (Symon et al., 2013), in England within a randomised controlled trial (Downe, 2011), in Germany and Switzerland (Grylka-Baeschlin et al., 2015), and is currently in use or planned for use in studies in the USA, Poland, Bolivia and the Czech Republic.

Having shown itself to be a versatile and widely-accepted instrument, it was selected for this Brazilian study which aimed to help raise awareness among health professionals about the reality of postnatal women's lives. Our ultimate intention is to help these health professionals to develop strategies to promote quality of life within this client group. To move towards achieving this aim we set out to translate and cross-culturally adapt the MGI for use in the Brazilian context. It is recognised that to produce a version of an instrument for use in another country and culture requires not just accurate linguistic translation but also an assurance of cultural equivalence (Herdman et al., 1997). In this paper we report this process as adopted in our study.

\section{Methods}

\section{The instrument}

The MGI is a single-sheet three step questionnaire. It avoids a 'top-down' approach by asking each mother to identify and then score only those aspects of her life which, following the birth of her baby, she considers to be important. In Step 1, she identifies these areas, stating if they are positive, negative or both/neither. In Step 2 she assigns a score to every aspect mentioned in Step 1 , from zero (worst) to 10 (best), based on how she has felt about this aspect over the previous month. The primary MGI score is the average of the Step 2 scores. In Step 3, the mother allocates 20 points among her cited areas according to the degree of importance they pose to her quality of life; this is a form of relative ranking.

\section{Translation and cross-cultural adaptation}

The process for translating and adapting the MGI followed that described by Beaton et al. (2007) (Flowchart 1).

Stage I - Initial Translation: Two independent translations of the MGI (T1 and T2) were made by a literature graduate with an expertise in semantic construction into Brazilian Portuguese and a healthcare professional who is proficient in the English language. Stage II - Translation synthesis: the two translations were synthesised and merged into a single preliminary tool (T-12) by the lead researcher (and first author). Stage III - T-12 was back-translated into English (BT1 and BT2) by two UK-based native English speakers who were fluent in Brazilian Portuguese but who did not know the original version of the scale. This stage is conducted in order to verify that the translated version duly reflects the same content as the original tool. Stage IV - This review by a committee of seven experts relates to content and face validation. To be confident about a tool's cultural adaptation, committee members should be experts in the study's field of interest. The committee comprised a linguistic specialist in the Portuguese language and four academic healthcare professionals, all of whom were

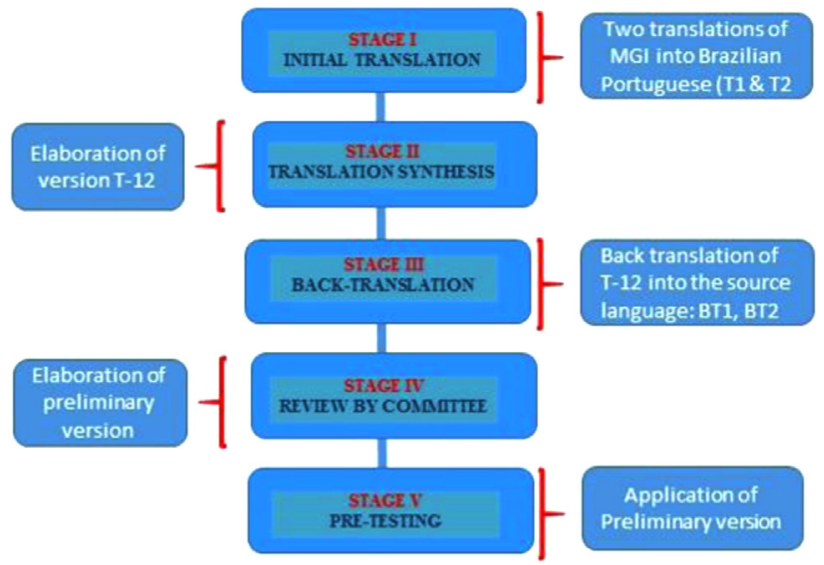

Flowchart 1. Translation and adaptation of the Mother-Generated Index into Brazilian Portuguese using Beaton et al.'s (2007) model . 
professors with PhDs. These four individuals had academic and practical experience in maternity care and in working with psychometric scales, including their creation, validation, use and evaluation. The committee evaluated the tool's semantic, idiomatic, experiential and conceptual equivalence, and subjected it to a Content Validity Index (CVI) (Martuza, 1977; Lynn, 1986). The CVI uses a 4-point scale (1 - Irrelevant; 2 - Little relevance; 3 Relevant; 4 - Very relevant) to assess the comprehension, accuracy and relevance of each statement or phrase within the tool. Data from this exercise were compiled in an Excel 7.0 spreadsheet. The CVI produces an index score of $0-1$ for each phrase or question where $1=100 \%$ agreement. The CVI was calculated from the average of the content validity indices for all statements (S-IVC/ Ave), the proportion of statements with a score of 3 (Relevant) and 4 (Very relevant) given by all experts (S-CVI/UA), and a content validation of the individual items (I-CVI) (Polit and Beck, 2006). According to Pasquali et al. (2010), 80\% of the judges have to agree on the relevance of a phrase or question.

Stage V - Pre-Testing of the tool on a population of 30 women, as recommended by Beaton et al. (2007). Mothers of term infants who had encountered no significant complications were eligible. They were identified from hospital records and contacted by a member of the research team (either the lead researcher [first author] or one of two colleagues [third and fourth authors]) using a consecutive non-probability sampling technique. They were interviewed at around 30 days post partum in their own home. The purpose of this stage is to check the adaptation of the translated content. Mothers were informed about the goals of the study, and assured about confidentiality and the freedom to decline participation without suffering any penalty. After reading the tool and discussing this with the first author, written consent was obtained.

Once this whole process of translation and adaptation had been completed and the tool assessed as valid, we recruited a further 91 mothers to explore their postnatal quality of life. These mothers were recruited as with the initial sample of 30 mothers, and interviewed at between 30 and 45 days post partum, again in their own home. We report the findings regarding quality of life in a separate paper.

Data collection was from May-August 2012. Participants completed the Brazilian Portuguese version of the MGI. These interviews lasted on average 20 minutes and were carried out by the first author. Socio-demographic data were analysed descriptively using the Statistical Package for the Social Sciences (SPSS) software (version 19.0).

This study was approved by the Research Ethics Committee of the Federal University of Ceará (Universidade Federal do Ceará; Protocol 086/11).

\section{Findings}

\section{Translation and cross-cultural adaptation}

Translations T1 and T2 were very similar, but it was felt that T1 was closer to the everyday language spoken by most people. Following synthesis (T-12) and back-translation (BT1 and BT2), the review by the committee of experts found no major differences between the back-translations and the original version of the tool. The committee made some minor changes to T-12 related to semantic equivalence, and applied the Content Validity Index (Table 1)

Six of the judges found that all the statements were understandable. One judge thought that citing examples in Step 1 was unnecessary, believing this could induce certain answers from the mothers. The total CVI score for the Brazilian version MGI was 0.90 , indicating a good level of overall agreement.
In the pre-testing phase (Stage V), 30 postpartum mothers completed the Brazilian Portuguese version of the MGI and their understanding of the tool was checked. MGI completion took between 10 and 16 minutes, and all mothers reported understanding Steps 1 and 2. However, several - particularly those with lower educational attainment levels - were unsure about the 'spending points' concept in Step 3. To address this, a strategy of offering 20 'spending beans' was used instead (Fig. 1). We decided to use beans as it is a regional food used daily by this population. This strategy facilitated understanding, and helped to speed up the time taken to complete the MGI. These mothers indicated that they preferred interview over self-completion for the MGI.

\section{Discussion}

The situation regarding obstetric intervention in Brazil has been well publicised in recent years (Cecatti, 2014; Declercq, 2014; Leal et al., 2014). The emphasis within postnatal care, as in many other countries, has traditionally been focussed principally on the baby, the mother's recovery being assumed (O'Reilly et al., 2009). However, more recently the significance of postnatal morbidity has been recognised (Souza et al., 2006; Mogos et al., 2013), but there has been no tool specifically adapted for use in Brazil which assesses subjective postnatal quality of life. It is vital when translating and culturally adapting instruments from elsewhere that a robust process is followed (Giusti and Befi-Lopes, 2008). During the initial stages of the translation process we noted the importance of selecting the right professionals to be involved. While we were conducting this study we became aware that a researcher in Portugal was also translating the MGI for use in her country. Portuguese as spoken in Brazil is essentially the same, but has certain significant differences and has been compared to the difference between English as spoken and written in the USA and as spoken and written in England (Boyce, 2014). Later comparison of the two versions revealed them to be very similar.

Cross-cultural adaptation of study instruments is a difficult, time-consuming, but arguably cost-effective process (Weeks et al., 2007). If conducted properly, it has the advantage that the translated study instruments are accurate, easy to understand, accessible, and culturally appropriate to the target audience, thereby producing valid and reliable data. The use of two translations usually highlights ambiguous meanings present in the original questionnaire, thus enhancing understanding by the target audience (Beaton et al., 2007). The participation of translators from different backgrounds at this stage was important as they brought different perspectives to bear; Beaton et al. (2007) note that this can promote the chance of an optimal translation. Research-active health professionals in any country have to ensure that novel instruments are acceptable to their target population, particularly when translated (Hanna et al., 2008). As Cha et al. (2007) note, it can be difficult to find appropriately qualified people who can ensure that a translated version achieves linguistic and cultural equivalence. We were fortunate to have the funding to acquire the necessary expertise for this aspect of the study, but are aware that this may not be the case for all researchers.

The back-translation stage is designed to check for gross conceptual errors or inconsistencies in the translations. Beaton et al. (2007) note that agreement between the original and the back-translation does not by itself guarantee the success of the procedure - it only ensures the consistency of the translation. If the translators do not represent the study's target population this can create difficulties (Wang et al., 2006). The most striking difference we found between BT1 and BT2 related to Step 1 and involved the words 'both', 'none' and 'neither', and to Step 2, involving the words 'best' and 'better'. Analysing the significance 
Table 1

Content Validity Index of MGI statements - Brazilian Portuguese version.

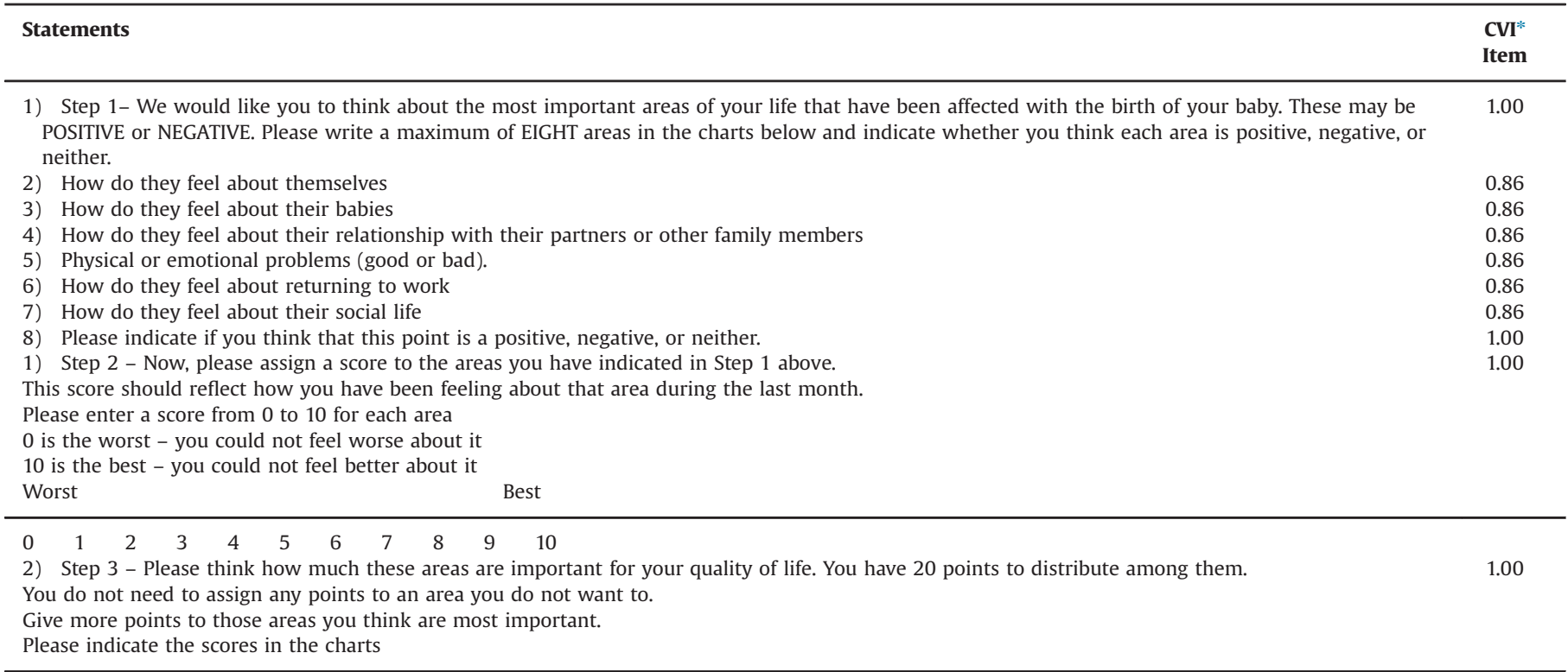

* CVI - Content Validity Index, where a score of $1.00=$ perfect agreement between seven committee members.

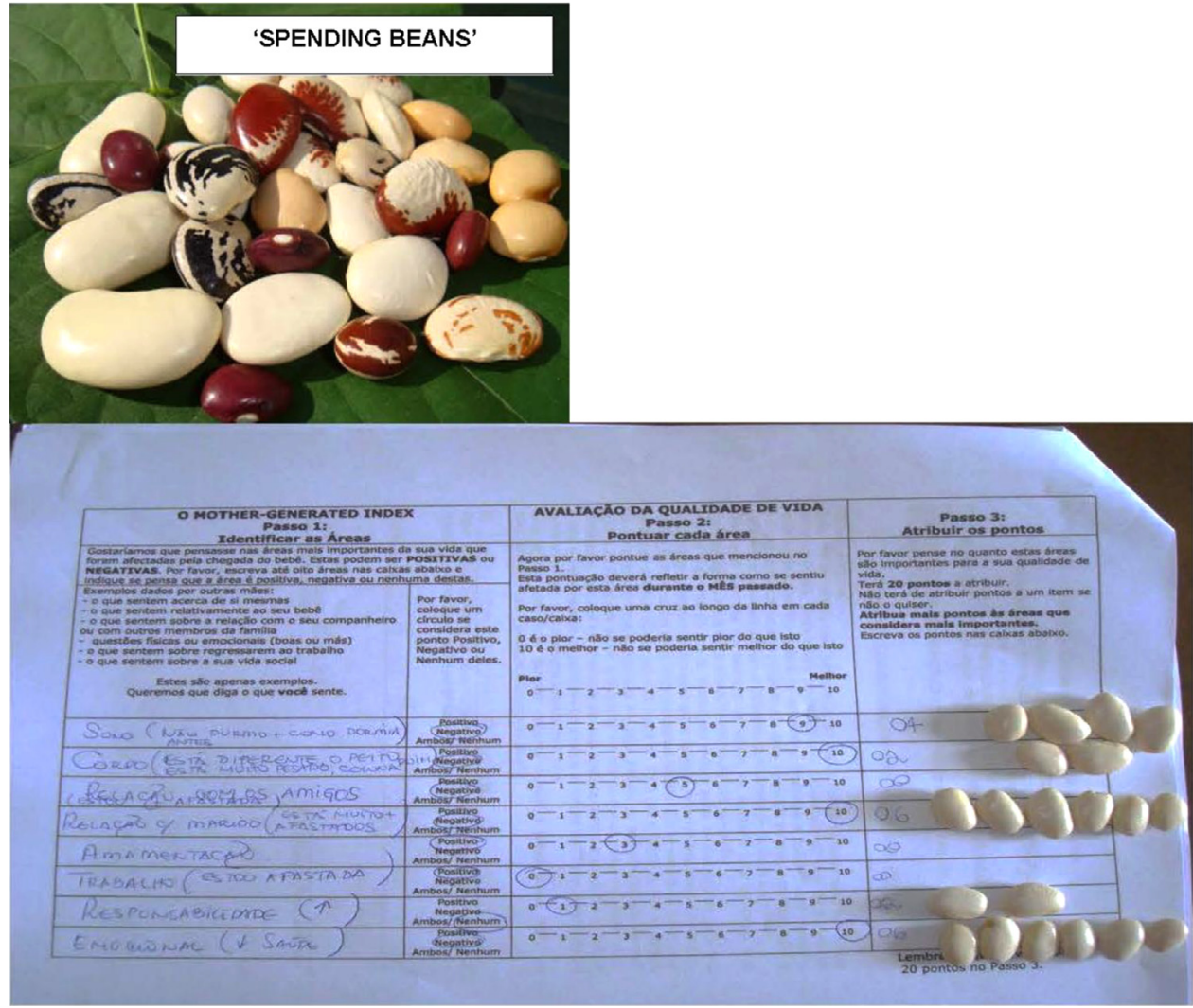

Fig. 1. 'Spending beans' used to facilitate completion of Step 3 of Brazilian-Portuguese MGI.

of these words' use in the English language allowed us to realise that in Portuguese they have practically the same meaning and therefore this did not represent a serious inconsistency that would hinder methodological progress.

The expert committee stage was a crucial aspect of the cultural adaptation process, and was carried out to verify the semantic, idiomatic, experiential and conceptual equivalence between the original document and the one produced for use in Brazil. The experts read and discussed the index together and then elaborated the preliminary version, following Beaton et al.'s (2007) prescribed approach, although it is intriguing that this stage of Beaton et al.'s process does not stipulate involving lay people or service users. If any of the experts disagreed or partially agreed with any of the tool items, the topic was put up for group discussion. The presence 
of a linguist here was considered essential. While this stage aims to ensure that the adapted version is indeed equivalent (Herdman et al., 1997), 'field testing' is the ultimate arbiter of whether this has been successful - as we ourselves found when we had to offer 'spending beans' in place of 'spending points'. Given the range of clinical areas and of research instruments it is no surprise to find that the process can be complicated and can require tailored solutions (Smit et al., 2006). Rahman et al. (2003) note that some studies demonstrate low sensitivity and specificity of translated tools, and Sperber (2004) concludes that this is a significant threat to study validity.

The MGI consists of only three steps with fairly simple instructions, and experience in several other countries indicates that it is not difficult to translate (Symon et al., 2013). In the current case, the main linguistic inconsistencies related to syntax, spelling and tenses of the sentences (i.e. semantic equivalence). At times some doubts arose as to which type of equivalence was under discussion, mainly between experiential and conceptual equivalences that are often difficult to tell apart. The advantage of having all translators present at the committee meeting was that any discrepancies were identified immediately and changes made accordingly.

Pasquali et al. (2010) note that content analysis consists of both semantic analysis and a theoretical analysis of the items. The semantic analysis (also known as face validation) aims mainly to ascertain that all index items are clear and understandable to the target population. On the other hand, the theoretical analysis has as one of its prerogatives the establishment of a group of 'expert' judges whose task is to check whether the tool actually measures what it intends to measure (Pasquali et al., 2010). Because of its subjectivity, content validation has been the target of some criticism within the scientific community and some strategies have been developed in order to increase its objectivity. One of them is the construction of the CVI, originally proposed by Martuza (1977) for educational use, but applied extensively within nursing research (Waltz and Bausell, 1981; Lynn, 1986; Grant and Davis, 1997). The division of the MGI into a list of statements allows the evaluation of the CVI by the experts, since each statement is equivalent to one item. In our case the overall CVI

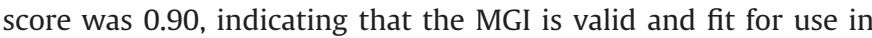
assessing the quality of life of postpartum women in Brazil.

Following this rigorous expert committee phase we implemented Stage V - the pre-testing of the tool with 30 mothers. The mothers indicated that interviews at home were preferable to being sent a postal questionnaire. While a range of options for survey completion is available using modern technology (Polit and Beck, 2012) a participant's lack of familiarity with an approach is likely to be an impediment. Experience elsewhere has suggested that the subjective 'bottom-up' approach of the MGI is not immediately familiar to mothers who are perhaps more used to a 'tick-box' questionnaire approach, but that having grasped the notion of suggesting areas of personal importance the process is quickly understood and even therapeutic (Symon et al., 2003a). This was found in the current study, and it was felt that the faceto-face element probably helped in this regard. However, we did encounter an apparent conceptual obstacle with Step 3 of the MGI. Being asked to use 'spending points' to produce a relative ranking of their cited areas seemed too abstract for some mothers. This feature was also encountered in an equivalent Iranian study (Khabiri et al., 2013), but is not mentioned in several other papers reporting the MGI, or the Patient-Generated Index (PGI) on which the MGI is based. This appeared to be an issue more for mothers whose educational levels were not high, and while our solution of providing 'spending beans' instead of 'spending points' got around this difficulty quickly, this does raise questions about questionnaire use with participants for whom form-filling is a challenge; this may be a particular issue in postal surveys. There is an obvious need to ensure that participants understand questions (Streiner and Norman, 2009) and are able to provide useful answers. If the researchers' underlying assumptions are not immediately obvious to participants this is clearly a problem. Researchers may prefer assessments to be standardised, but they must recognise the need to alter process to suit individual capability. Involving service users in the development of health measurement or quality of life scales is well established (Mcdowell, 2009), and may help to address this issue. We would advise extending service user involvement to the process of culturally adapting instruments, something which was not advocated in the model we used.

Face-to-face interviewing has several advantages: the interviewer knows who is responding (Streiner and Norman, 2009), and can check levels of comprehension, rectifying misunderstandings where necessary. The introduction of 'spending beans', as described above, is an example. This simple use of an everyday object satisfactorily overcame a conceptual block; this approach may be a useful tool for researchers dealing with people who struggle with written numbers. As this strategy worked well we continued to use the spending beans in the next phase of the study, and in a separate paper we report findings concerning the quality of life of 91 mothers. The MGI allows for a simple and understandable way to assess the different dimensions of quality of life. As our ultimate intention was to help health professionals to develop strategies to promote quality of life within this client group, we believe that the adaptation for use within Brazil of this tool offers healthcare professionals the opportunity to become aware of all aspects of a woman's life that are altered after the birth of the baby. It is vital to gain this holistic perspective since quality of life includes but is not limited to health-related matters; co-operation with other agencies is likely to be important. Administering the MGI by interview also means the woman does not have to be literate: as long as she is able to articulate her thoughts the researcher/health professional can transcribe these for her (Symon et al., 2013).

On reflection the research team felt that the detailed information provided by the MGI provides subjective information which would not be forthcoming using a structured questionnaire such as the Maternal PostPartum Quality Of Life (MAPP-QOL) instrument (Hill et al., 2006). However, to assess this, a comparative study using both instruments is planned.

We acknowledge that the study had several limitations. As mentioned above, the expert review panel did not anticipate the difficulties that some mothers encountered with the Step 3 part of the MGI. While a solution was found for this, this demonstrates that there is no substitute for field testing of an instrument. The field testing reported here was with just 30 mothers, although the next phase of the study did involve a further 91 mothers. The mothers in this study indicated that face-to-face interviews were preferable to completing a postal questionnaire. While this has methodological advantages, it is also more expensive and therefore may be a limiting factor for some researchers. Although the purpose of this paper is to report the process of the translation and cultural adaptation, the study which formed the backdrop also had limitations: it was geographically specific, being located in one city in northern Brazil. Differences in dialect may mean that some phrases need to be altered elsewhere in the country, although dialect differences are not pronounced despite Brazil's size, and in this study this was not felt to be an issue.

\section{Conclusion}

A thorough and well formulated approach was required to ensure that the translated and culturally adapted tool was appropriate for 
use within Brazil. Although the MGI is a short instrument consisting of just a few sentences, we followed the Beaton et al. (2007) prescribed approach strictly, seeking to maximise the MGI's similarity to the content of the original tool. The high Content Validity Index score awarded by a committee of experts indicates that it reflected the original instrument closely and should therefore be an appropriate tool for the subjective assessment of postnatal quality of life. However, while face validity was good, we encountered a conceptual obstacle in mothers with lower educational levels. The use of a physical 'currency', in the form of 'spending beans' instead of 'spending points', solved this problem. These discussions with mothers led us to conclude that the MGI needs to be administered face-to-face, at least in the first instance. This echoes the findings from other studies using this tool.

The process of translation and expert review does require considerable resources, and these may not be available to all researchers. However, we are satisfied that we have now addressed one of the gaps in the evidence base - namely the lack of a subjective quality of life tool for postnatal women in Brazil. Such a study can only represent an incremental advance, and we are currently engaged in testing the tool further with a larger sample. Given the complexity of this topic, not least in Brazil with its economic disparities and peculiar obstetric tradition, multiagency work is likely to be required to make significant improvements in postnatal quality of life.

\section{Funding}

Funding for this study was secured from FUNCAP/CAPES (Fundação Cearense de Apoio do Desenvolvimento Científico e Tecnológico/Coordenação de Aperfeiçoamento de Pessoal de Nível Superior, Brazil) (Grant number Acordo FUNCAP/CAPES edital 01/ 2014).

\section{Conflict of interest}

The authors declare that they had no conflict of interest in the production of this paper.

\section{References}

Barros, F., Victora, C., Vaughan, J., Huttly, S., 1991. Epidemic of caesarean sections in Brazil. Lancet 338, 167-169.

Beaton, D., Bombardier, C., Guillemin, F., Ferraz, M., 2007. Recommendations for the Cross-Cultural Adaptation of the DASH and QuickDASH Outcome Measures. Institute for Work and Health 〈http://www.dash.iwh.on.ca/system/files/X-Cul turalAdaptation-2007.pdf (accessed 5 January 2015).

Boyce, P., 2014. Portuguese: The World's Seventh Most Spoken Language. British Council 〈http://www.britishcouncil.org/blog/portuguese-worlds-seventh-mostspoken-language $\rangle$ (accessed 6 January 2015).

Calman, K.C., 1984. Quality of life in cancer patients - a hypothesis. J. Med. Ethics $10,124-127$.

Cecatti, J.G., 2014. Beliefs and misbeliefs about current interventions during labor and delivery in Brazil. Cad. de Saúde Pública 30, S23-S24.

Cha, E.-S., Kim, K., Erlen, J., 2007. Translation of scales in cross-cultural research: issues and techniques. J. Adv. Nurs. 58, 386-395.

Declercq, E., 2014. Is medical interventions in childbirth inevitable in Brazil? Cad. de Saúde Pública 30, S17-S18.

Downe, S., 2011. Trial Registration: Self-Hypnosis for Intrapartum Pain management (SHIP). 〈http://www.controlled-trials.com/ISRCTN27575146〉.

Giusti, E., Befi-Lopes, D., 2008. Translation and cross-cultural adaptation of instruments to the Brazilian Portuguese language [Tradução e adaptação transcultural de instrumentos estrangeiros para o Português Brasileiro (PB)]. Pró-Fono Rev. de Atualização Cient. 20, 207-210.

Grant, J., Davis, L., 1997. Selection and use of content experts in instrument development. Res. Nurs. Health 20, 269-274.

Grylka-Baeschlin, S., Van Teijlingen, E., Stoll, K., Gross, M., 2015. Translation and validation of the German version of the Mother-Generated Index and its application during the postnatal period. Midwifery 31, 47-51. http://dx.doi. org/10.1016/j.midw.2014.05.002.
Hanna, L., Hunt, S., Bhopal, R., 2008. Insights from research on cross-cultural validation of health-related questionnaires: the role of bilingual project workers and lay participants. Curr. Sociol. 56, 115-131.

Herdman, M., Fox-Rushby, J., Badia, X., 1997. "Equivalence" and the translation and adaptation of health-related quality of life questionnaires. Qual. Life Res. 6, 237-247.

Hill, P., Aldag, J., Hekel, B., Riner, G., Bloomfield, P., 2006. Maternal postpartum quality of life questionnaire. J. Nurs. Meas. 14, 205-220.

hscic [Health and Social Care Information Centre], 2014. Patient-Reported Outcome Measures (PROMs). 〈http://www.hscic.gov.uk/proms〉 (accessed 5 January 2015).

Kanotra, S., D’angelo, D., Phares, T.M., Morrow, B., Barfield, W.D., Lansky, A., 2007. Challenges faced by new mothers in the early postpartum period: an analysis of comment data from the 2000 Pregnancy Risk Assessment Monitoring System (PRAMS) survey. Matern. Child Health J. 11, 549-558.

Khabiri, R., Rashidian, A., Montazeri, A., et al., 2013. Validation of the MotherGenerated Index in Iran: a specific postnatal quality of life instrument. Int. J. Prev. Med. 4, 1371-1379.

Kyser, K., Lu, X., Santillan, D., et al., 2012. The association between hospital obstetrical volume and maternal postpartum complications. Am. J. Obstet. Gynecol. 207, 42.e1-42.e17.

Leal, M.D.C, Pereira, A.P.E., Domingues, R.M.S.M., et al., 2014. Obstetric interventions during labor and childbirth in Brazilian low-risk women. Cad. de Saúde Pública 30, S1-S16.

Lynn, M., 1986. Determination and quantification of content validity. Nurs. Res. 35, 382-385.

Mapi Research Trust, 2014. PROQOLID: Patient-Reported Outcome and Quality of Life Instruments Database. 〈http://www.proqolid.org〉 (accessed 5 January 2015).

Martuza, V., 1977. Applying Norm-Referenced and Criterion-Referenced Measurement in Education. Allyn and Bacon, Boston.

Mcdowell, I., 2009. Measuring Health: A Guide to Rating Scales and Questionnaires Oxford Scholarship Online, Oxford.

Ministry of Health, Brazil [Ministério da Saúde, Brasil], 2005. Prenatal and puerperium: qualified and humanized care - technical manual [Pré-natal e Puerpério: atenção qualificada e humanizada - manual técnico]. Secretaria de Atenção à Saúde, Departamento de Ações Programáticas Estratégicas. Série Direitos Sexuais e Direitos Reprodutivos, Caderno $n^{\circ} 5$, Ministério da Saúde, Brasília.

Ministry of Health, Brazil [Ministério da Saúde, Brasil], 2012. Care of low risk pregnant women [Atenção ao pré-natal de baixo risco]. Secretaria de Atenção à Saúde. Departamento de Atenção Básica. Série A. Normas e Manuais Técnicos, Cadernos de Atenção Básica, ñ 32, Editora do Ministério da Saúde Brasília.

Mogos, M., August, E., Salinas-Miranda, A., Sultan, D., Salihu, H., 2013. A systematic review of quality of life measures in pregnant and postpartum mothers. Appl. Res. Qual. Life 8, 219-250.

Nagpal, J., Sengupta, R., Sinha, S., Bhargava, V., Sachdeva, A., Bhartia, A., 2008. An exploratory study to evaluate the utility of an adapted Mother Generated Index (MGI) in assessment of postpartum quality of life in India. Health Qual. Life Outcomes 6, 107. http://dx.doi.org/10.1186/1477-7525-6-107.

Nowakowska-Głab, A., Maniecka-Bryła, I., Wilczyński, J., Nowakowska, D., 2010. Evaluation of antenatal quality of life of hospitalized women with the use of Mother-Generated Index - pilot study. Ginekol. Polska 81, 521-527.

O’Reilly, R., Peters, K., Beale, B., Jackson, D., 2009. Women's experiences of recovery from childbirth: focus on pelvis problems that extend beyond the puerperium. J. Clin. Nurs. 18, 2013-2019.

Pasquali, L., Capovilla, A., Alonso, A., Alves, A., Borba, A., Batista, C., 2010. Psychological Instrumentation - Fundamentals and Practices [Instrumentação psicológica - Fundamentos e práticas]. Artmed, Porto Alegre.

Pereira, M.C., Gradim, C.V.C., 2014. Puerperal consultation from the perspective of nurses and puerperae [Consulta puerperal: a visão do enfermeiro e da puérpera]. Ciência Cuidado e Saúde 13, 35-42.

Polit, D., Beck, C., 2006. The content validity index: are you sure you know what's being reported? Critique and recommendations, Res. Nurs. Health 29 , 489-497.

Polit, D., Beck, C., 2012. Nursing Research: Generating and Assessing Evidence for Nursing Practice. Lippincott Williams and Wilkins, Philadelphia, PA.

Potter, J., Berquó, E., Perpétuo, I., et al., 2001. Unwanted caesarean sections among public and private patients in Brazil: prospective study. Br. Med. J. 323 1155-1158.

Rahman, A., Iqbal, Z., Waheed, W., Hussain, N., 2003. Translation and cultural adaptation of health questionnaires. J. Pak. Med. Assoc. 53, 142-147.

Smit, J., van den Berg, C.E., Bekker, L.-G., Seedat, S., Stein, D.J., 2006. Translation and cross-cultural adaptation of a mental health battery in an African setting. Afr Health Sci. 6, 215-222.

Souza, J., Cecatti, J., Parpinelli, M., De Sousa, M., Serruya, S., 2006. Systematic review of near miss maternal morbidity [Revisão sistemática sobre morbidade materna near miss]. Cad. de Saúde Pública 22, 255-264.

Sperber, A.D., 2004. Translation and validation of study instruments for crosscultural research. Gastroenterology 126, S124-S128.

Streiner, D., Norman, G., 2009. Health Measurement Scales: A Practical Guide to their Development and Use. OUP, Oxford.

Symon, A., Mackay, A., Ruta, D., 2003a. Postnatal quality of life: a pilot study using the Mother-Generated Index. J. Adv. Nurs. 42, 21-29.

Symon, A., Mcgreavey, J., Picken, C., 2003b. Validation of the Mother-Generated Index. Br. J. Obstet. Gynaecol. 110, 865-868. 
Symon, A., Nagpal, J., Maniecka-Bryła, et al., 2013. Cross-cultural adaptation and translation of a quality of life tool for new mothers: a methodological and experiential account from six countries. J. Adv. Nurs. 69, 970-980.

Waltz, C., Bausell, R., 1981. Nursing Research: Design, Statistics, and Computer Analysis. F.A. Davis, Philadelphia, PA.

Wang, W.-L., Lee, H.-L., Fetzer, S, 2006. Challenges and strategies on instrument translation. West. J. Nurs. Res. 28, 310-321.
Weeks, A., Swerissen, H., Belfrage, J., 2007. Issues, challenges, and solutions in translating study instruments. Eval. Rev, 31, 153-165.

Yelland, J., 2010. Women's and midwives' views of early postnatal care. In: Byrom, S., Edwards, G., Bick, D. (Eds.), Essential Midwifery Practice: Postnatal Care. Wiley-Blackwell, Chichester. 